\title{
BMJ Open Shared decision-making as a cost-containment strategy: US physician reactions from a cross-sectional survey
}

\author{
Jon C Tilburt, ${ }^{1}$ Matthew K Wynia, ${ }^{2}$ Victor M Montori, ${ }^{3}$ Bjorg Thorsteinsdottir, ${ }^{4}$ \\ Jason S Egginton, ${ }^{5}$ Robert D Sheeler, ${ }^{6}$ Mark Liebow, ${ }^{1}$ Katherine M Humeniuk, ${ }^{7}$ \\ Susan Dorr Goold ${ }^{8}$
}

To cite: Tilburt JC,

Wynia MK, Montori VM, et al. Shared decision-making as a cost-containment strategy: US physician reactions from a cross-sectional survey. BMJ Open 2014;4:e004027. doi:10.1136/bmjopen-2013004027

- Prepublication history and additional material for this paper is available online. To view these files please visit the journal online (http://dx.doi.org/10.1136/ bmjopen-2013-004027)

Received 13 September 2013 Revised 4 December 2013 Accepted 5 December 2013

CrossMark

For numbered affiliations see end of article

Correspondence to Dr Jon C Tilburt; tilburt.jon@mayo.edu

\section{ABSTRACT}

Objective: To assess US physicians' attitudes towards using shared decision-making (SDM) to achieve cost containment.

Design: Cross-sectional mailed survey.

Setting: US medical practice.

Participants: 3897 physicians were randomly selected from the AMA Physician Masterfile. Of these, 2556 completed the survey.

Main outcome measures: Level of enthusiasm for "Promoting better conversations with patients as a means of lowering healthcare costs"; degree of agreement with "Decision support tools that show costs would be helpful in my practice" and agreement with "should promoting SDM be legislated to control overall healthcare costs".

Results: Of 2556 respondents (response rate (RR) $65 \%)$, two-thirds (67\%) were 'very enthusiastic' about promoting SDM as a means of reducing healthcare costs. Most $(70 \%)$ agreed decision support tools that show costs would be helpful in their practice, but only $24 \%$ agreed with legislating SDM to control costs.

Compared with physicians with billing-only compensation, respondents with salary compensation were more likely to strongly agree that decision support tools showing costs would be helpful (OR $1.4 ; 95 \% \mathrm{Cl} 1.1$ to 1.7 ). Primary care physicians (vs surgeons, OR 1.4; $95 \% \mathrm{Cl} 1.0$ to 1.6 ) expressed more enthusiasm for SDM being legislated as a means to address healthcare costs.

Conclusions: Most US physicians express enthusiasm about using SDM to help contain costs. They believe decision support tools that show costs would be useful. Few agree that SDM should be legislated as a means to control healthcare costs.

\section{INTRODUCTION}

Since at least in the 1980s, shared decisionmaking (SDM), defined as a process of patient engagement and mutual deliberation between healthcare providers and patients, ${ }^{1}$ has been advanced as a way to promote respect for patients, encourage greater

\section{Strengths and limitations of this study}

- Although barriers to shared decision-making (SDM) have been previously described, this is the first study, to our knowledge, describing the US physicians' views about SDM as a means of reducing healthcare costs.

- Our study suggests that most US physicians are enthusiastic about SDM and see it as a promising avenue for controlling costs, but only a minority of physicians agree that SDM should be legislated to help control healthcare costs.

- While this cross-sectional survey had a solid response rate, reducing concerns about response bias, its findings should still be treated with caution due to the nature of the topic area. Social desirability may lead physicians to say very glowing things about SDM; whether their behaviour follows was not addressed.

- Ascertaining motivations behind the opinions we report here would require further in-depth qualitative work beyond the scope of this survey.

patient engagement in their care and improve adherence and outcomes. ${ }^{2}$ SDM interventions such as decision aids (DAs) enhance patient knowledge, assist patients in forming realistic expectations, clarify their preferences and decrease decisional conflict. ${ }^{3-5}$ In addition, there is some evidence that using certain SDM tools like DAs can reduce utilisation of discretionary procedures $^{6}$ and perhaps even reduce overall healthcare expenditures and utilisation..$^{5-7}$

Efforts are underway to use SDM as a means of addressing healthcare costs. Some advocates propose including physicians' use of DAs as a quality measure aimed at controlling discretionary healthcare spending. ${ }^{8}$ The Patient Protection and Affordable Care Act (ACA) introduced several provisions to promote the use of SDM, ${ }^{9}$ including Centers for Medicare \& Medicaid Services (CMS) innovation initiatives aimed at testing SDM as 
a means of reducing discretionary procedures and lowering costs. ${ }^{8}$ While general barriers to SDM in physician practice have been described, ${ }^{10}$ it is not known whether physicians charged with carrying out SDM find it an attractive means of reducing healthcare costs, whether they would endorse using decision support tools that show costs or whether they endorse the idea of legislation promoting SDM for the purpose of controlling healthcare costs as an appropriate means of achieving cost savings.

\section{METHODS}

The Mayo Clinic Institutional Review Board approved this study. In May 2012, we mailed a self-administered, eight-page survey entitled, "Physicians, Healthcare Costs, and Society" to a random sample of 3897 practicing US physicians representing all specialties listed in the AMA Physician Masterfile using the Tailored Design Method ${ }^{11}$ including a US $\$ 20$ bill with the first mailing only. Second and third mailings were sent to non-responders at 6 -week intervals.

\section{Survey instrument}

To develop our instrument, we reviewed the literature, surveyed five focus groups with physicians, formulated questions, conducted eight cognitive interviews and revised questions, adapting or adopting existing measures whenever possible including the Agreement with Rationing Scale ${ }^{12}$ the six-item Cost-Consciousness Scale ${ }^{13}$ and two items from a Stewardship Scale developed by the American Medical Association's Institute for Ethics (Wynia M. Personal communication, April 2012). The final survey includes questions assessing the physicians' perspectives on healthcare reform, their societal responsibilities, medical decision-making, cost of healthcare and costconscious practices. The results focusing on those measures are reported elsewhere. ${ }^{14}$ This report focuses on measures pertaining to the use of and barriers to SDM particularly as it relates to healthcare costs. (Full instrument is available in online supplementary appendix A.)

\section{Measures}

Three outcome measures assessed the respondents' attitudes towards SDM and cost. First, we assessed the respondents' level of enthusiasm (not, somewhat, very) for SDM as a strategy to reduce healthcare costs. We operationalised that idea in the phrase, "Promoting better conversations with patients" as a means of lowering healthcare costs. Second, we also asked for respondents' degree of agreement with "Decision support tools that show costs would be helpful in my practice" (strongly disagree, moderately disagree, moderately agree, strongly agree); and finally, we asked "Should promoting SDM be legislated to control overall healthcare costs" (yes/no).

We examined physician demographics (age, sex, region, specialty type and political self-characterisation), practice characteristics (compensation type, predominant practice setting type) as well as perceived barriers to SDM drawn from the literature ("Which of the following is a major barrier to you more actively engaging patients in a process of SDM?" [mark all that apply] patient confusion, inability to individualise risk, lack of patient interest in playing an active role, lack of supportive systems, lack of adequate time with the patient, administrative burdens, financial pressure to do better paying activities, other) as important covariates of their receptivity to SDM being used as a cost-containment strategy.

\section{Analysis}

Using SAS V.9.2 (Cary, North Carolina, USA), we calculated response distributions for all items related to SDM previously described. We performed bivariate and multivariate tests of association (ie, unadjusted and adjusted logistic regression models) to examine the associations between physician characteristics (sex, age, region of practice, specialty, practice setting type, compensation type and political self-characterisation) as well as attitudes about barriers to SDM (independent measures) and their views on each of the three dimensions of SDM as a cost-containment strategy (dependent measures) described above. The dependent measures assessing the enthusiasm for 'better conversations' as a costcontainment strategy and "Decision support tools that show costs would be helpful in my practice" were subsequently dichotomised for ease of presentation (very enthusiastic vs all others and strongly agree vs all others, respectively). Variables included in multivariate logistic regression models were determined based on those characteristics of physicians that we a priori hypothesised would be associated with our dependent variables (ie, age, sex, region of practice, specialty type and political self-characterisation), as well as physician characteristics and survey items that were empirically found in bivariate analyses to be significantly associated with our three dependent variables of interest (ie, practice setting, practice compensation type and perceived barriers to implementing SDM). Therefore, for each dependent variable, we first ran a 'base model' containing only those variables for which we were adjusting (age, sex, region of practice, specialty type and political self-characterisation), and then subsequently conducted separate multivariable models testing the association between each individual characteristic/attitude and the dependent variable while controlling for age, sex, region of practice, specialty type and political self-characteriation.

\section{RESULTS}

In total 2556 physicians responded to the survey $(65 \%$ response rate) ${ }^{15}$ Respondents were largely male (70\%), age 50 years or older $(58 \%)$ and white $(77 \%$; table 1$)$. The respondents were slightly older than nonrespondents (58\% vs $54 \%$ older than 50 years, respectively; $\left.\chi^{2}=5.4 ; \mathrm{p}=0.02\right)$ but otherwise representative of the overall US physician population. ${ }^{16}$ Most $(67 \%)$ of them 
Table 1 Characteristics of 2556 responding US physicians, as well as their perceived barriers to shared decision-making

\begin{tabular}{|c|c|}
\hline Characteristic & $\mathbf{N}(\%)$ \\
\hline Age, mean (SD), years & $51.0(8.5)$ \\
\hline Male sex & $1784(70)$ \\
\hline \multicolumn{2}{|l|}{ Race or ethnic group* } \\
\hline White or Caucasian & $1958(77)$ \\
\hline Asian & 369 (15) \\
\hline Other & $124(5)$ \\
\hline Black or African-American & $80(3)$ \\
\hline \multicolumn{2}{|l|}{ Region† } \\
\hline South & $829(33)$ \\
\hline Midwest & $594(23)$ \\
\hline Northeast & $548(22)$ \\
\hline West & $570(22)$ \\
\hline \multicolumn{2}{|l|}{ Primary specialty } \\
\hline Primary care & $1034(40)$ \\
\hline Surgery & $571(22)$ \\
\hline Procedural specialty & 486 (19) \\
\hline Non-procedural specialty & $399(16)$ \\
\hline Non-clinical & $44(2)$ \\
\hline \multicolumn{2}{|l|}{ Practice setting type } \\
\hline Group/HMO & $1641(64)$ \\
\hline Small/solo & 498 (19) \\
\hline City/state/federal government & $336(13)$ \\
\hline Medical school & $59(2)$ \\
\hline \multicolumn{2}{|l|}{ Practice compensation type $\ddagger$} \\
\hline Billing only & $1036(41)$ \\
\hline Salary plus bonus & $874(35)$ \\
\hline Salary only & $460(18)$ \\
\hline Other & $154(6)$ \\
\hline \multicolumn{2}{|l|}{ Political self-characterisation§ } \\
\hline Very conservative & $254(10)$ \\
\hline Somewhat conservative & 709 (28) \\
\hline Independent/moderate & $726(29)$ \\
\hline Somewhat liberal/progressive & $495(20)$ \\
\hline Very liberal/progressive & $247(10)$ \\
\hline \multicolumn{2}{|c|}{$\begin{array}{l}\text { Which of the following is a major barrier to you more actively engaging patients in } \\
\text { a process of shared decision-making? }(n=2402) \emptyset\end{array}$} \\
\hline Patient confusion & $1558(65)$ \\
\hline Lack of patient interest in playing an active role & $1425(59)$ \\
\hline Lack of adequate time with the patient & $1349(56)$ \\
\hline Administrative burdens & $808(34)$ \\
\hline Inability to individualise risk & $499(21)$ \\
\hline Financial pressure to do better paying activities & $349(15)$ \\
\hline Other & $268(11)$ \\
\hline Lack of supportive systems & $216(9)$ \\
\hline
\end{tabular}

*Percentages based on a denominator of 2532.

tPercentages based on a denominator of 2541.

$\ddagger$ Percentages based on a denominator of 2524.

§Percentages based on a denominator of 2497.

ףltem was 'Mark all that apply'; hence percentages here were calculated with the denominator as the total number of respondents who answered this question (ie, selected at least one of the response category options).

$\mathrm{HMO}$, Health Maintenance Organization.

were 'very enthusiastic' about promoting better conversations with patients as a means of reducing healthcare costs. A majority of the respondents somewhat or strongly agreed that decision support tools that show costs would be helpful in their practice $(70 \%)$. In contrast, only one in four respondents $(24 \%)$ agreed that promoting SDM should be legislated as a means of controlling healthcare costs (table 2). The most common barriers to SDM are summarised in table 1.

When stratifying respondents by demographic characteristics (age, sex, region, specialty and political self-characterisation), we found that a majority of respondents from all subgroups expressed enthusiasm about SDM as a cost-containment strategy and decision 


\begin{tabular}{|c|c|}
\hline Survey item & No. (\%) \\
\hline \multicolumn{2}{|c|}{$\begin{array}{l}\text { Level of enthusiasm for "promoting better conversations } \\
\text { with patients" as a means to promote cost containment } \\
(n=2486)\end{array}$} \\
\hline Not enthusiastic & $80(3)$ \\
\hline Somewhat enthusiastic & $745(30)$ \\
\hline Very enthusiastic & $1661(67)$ \\
\hline \multicolumn{2}{|c|}{$\begin{array}{l}\text { Decision support tools that show costs would be helpful in } \\
\text { my practice }(n=2461)\end{array}$} \\
\hline Strongly disagree & $251(10)$ \\
\hline Somewhat disagree & 487 (20) \\
\hline Somewhat agree & $1240(50)$ \\
\hline Strongly agree & $483(20)$ \\
\hline \multicolumn{2}{|c|}{$\begin{array}{l}\text { Promoting SDM should be legislated as a means of } \\
\text { controlling healthcare costs }(n=2435)\end{array}$} \\
\hline Yes & $593(24)$ \\
\hline No & $1842(76)$ \\
\hline
\end{tabular}

support tools that show costs. In contrast, a consistent minority of respondents across all subgroups agreed that promoting SDM should be legislated (table 3).

In bivariate analyses, female physicians (OR 1.7; 95\% CI 1.4 to 2.1 ) and those identifying as politically liberal (OR 1.8; 95\% CI 1.5 to 2.3 ) had significantly greater odds of being very enthusiastic about promoting better conversations as a means to reduce healthcare costs. Surgeons had lower odds than primary care providers to express enthusiasm for promoting better conversations as a means of cost containment (OR $0.7 ; 95 \%$ CI 0.6 to 0.9 ), while responding physicians' region of practice, age and type of practice setting did not appear to be associated with their views on this item.

In separate multivariable models adjusted for age, sex, region, specialty and political self-characterisation, respondents reporting salary/salary + bonus compensation compared with billing-only had a greater odds of strongly agreeing that decision support tools that show costs would be helpful in their practice (OR 1.4; 95\% CI 1.1 to 1.7$)$. Respondents identifying themselves as "very or somewhat liberal or progressive" also had higher odds than those self-described as "very or somewhat conservative" of strongly agreeing that decision support tools that show cost would be helpful (OR 2.2; 95\% CI 1.7 to 2.9), as well as expressing strong enthusiasm for promoting better conversations with patients (OR 1.7; 95\% CI 1.4 to 2.1 ; table 4 ).

Several perceived barriers to SDM were independently associated with the respondents' enthusiasm about promoting better conversations with patients as a costcontainment strategy, whether decision support tools showing costs would be helpful and whether SDM should be legislated to control healthcare costs. In logistic regression models adjusted for sex, age, region, specialty and political self-characterisation, those who selected 'lack of supportive systems' as a perceived barrier to SDM had twice the odds (OR 2.1; 95\% CI 1.4 to 3.0) as others to be very enthusiastic about promoting better conversations with patients as a means of reducing healthcare costs. Respondents who perceived administrative burdens (OR 1.3; 95\% CI 1.0 to 1.6) and lack of supportive systems (OR 1.5; 95\% CI 1.1 to 2.1 ) as barriers to SDM also had significantly higher odds of strongly agreeing that decision support tools showing costs would be helpful in their practice. Finally, respondents who selected administrative burdens (OR 1.4; 95\% CI 1.1 to 1.7 ), an inability to individualise risk (OR 1.5; 95\% CI 1.2 to 1.9), financial pressure to perform betterpaying activities (OR 1.6; 95\% CI 1.2 to 2.1 ) and lack of supportive systems (OR 2.0; 95\% CI 1.5 to 2.7) as perceived barriers to SDM had greater odds of believing that SDM should be legislated (table 4).

\section{DISCUSSION}

Most of the US physicians express a strong enthusiasm for promoting better conversations with patients as a means to control healthcare costs and believe decision support tools showing costs would be useful. A minority of physicians agree that SDM should be legislated to help control healthcare costs. Although certain subgroups of respondents (eg, self-described liberals; women) appear more likely to express enthusiasm for SDM and cost transparency compared with other subgroups, majority of respondents in all subgroups were, overall, supportive of promoting better conversations and using decision support tools that show costs.

\section{Comparison with other studies}

Given the significant variability of cost and lack of cost transparency in the US health system, ${ }^{17-21}$ decision support tools that show total costs and patient out-of-pocket costs could be a means to empower physicians and patients as informed healthcare consumers. Support innovations that promote cost transparency also might reflect physicians' views of patient responsibility for reducing healthcare costs. In any event, promoting tools to achieve better conversations with patients and cost transparency appears to be a physician-supported, patient-centered strategy for achieving a higher quality care that may also achieve cost containment as well.

Lack of time with patients and administrative barriers pose obstacles to engaging patients in SDM, according to our respondents. Two of the barriers to SDM that physicians cited-patient's confusion and patients' lack of interest-stand in contrast to studies of patients' views. The national 2009 DECISIONS study ${ }^{22}$ of nine medical decisions found patients say they are ready for involvement and desire it. There are multiple explanations for this gap. First, while patients say, when asked, they want to play a greater role in decision-making, doctors may interpret their behaviour during encounters otherwise. Expressions of preference for decision- 
Table 3 Distribution of physician responses to SDM-related survey items stratified by demographic characteristics

\begin{tabular}{|c|c|c|c|c|c|c|}
\hline & \multicolumn{2}{|c|}{$\begin{array}{l}\text { Very enthusiastic } \\
\text { about promoting } \\
\text { better conversations } \\
\text { as means to reduce } \\
\text { healthcare costs }\end{array}$} & \multicolumn{2}{|c|}{$\begin{array}{l}\text { Agree decision } \\
\text { support tools } \\
\text { showing costs } \\
\text { would be helpful in } \\
\text { my practice }\end{array}$} & \multicolumn{2}{|c|}{$\begin{array}{l}\text { Promoting SDM } \\
\text { should be legislated }\end{array}$} \\
\hline & $\mathrm{N}$ (row \%) & p Value & N (row \%) & p Value & $\mathrm{N}$ (row \%) & p Value \\
\hline Age (years) & & 0.48 & & 0.82 & & $<0.0001$ \\
\hline Less than 50 years $(n=1043)$ & $705(68)$ & & $710(69)$ & & $293(29)$ & \\
\hline 50 years or greater $(n=1443)$ & $956(66)$ & & $1013(71)$ & & $300(21)$ & \\
\hline Sex & & $<0.0001$ & & 0.24 & & 0.19 \\
\hline Male $(n=1734)$ & $1097(63)$ & & $1199(70)$ & & $405(24)$ & \\
\hline Female $(n=752)$ & $564(75)$ & & $524(70)$ & & $188(26)$ & \\
\hline Region & & 0.99 & & 0.01 & & 0.69 \\
\hline Midwest $(n=570)$ & $379(66)$ & & $420(74)$ & & $133(24)$ & \\
\hline South $(n=809)$ & $539(67)$ & & $550(69)$ & & $183(23)$ & \\
\hline West $(n=555)$ & $369(66)$ & & 392 (72) & & $132(24)$ & \\
\hline Northeast $(n=537)$ & $361(67)$ & & $351(66)$ & & $136(26)$ & \\
\hline Primary specialty & & 0.05 & & 0.26 & & 0.02 \\
\hline Primary care $(n=1003)$ & $693(69)$ & & $711(71)$ & & $247(25)$ & \\
\hline Surgery $(n=558)$ & $348(62)$ & & 369 (67) & & $104(19)$ & \\
\hline Procedural specialty $(n=473)$ & $310(66)$ & & $334(72)$ & & $126(27)$ & \\
\hline Nonprocedural specialty $(n=390)$ & $273(70)$ & & $264(68)$ & & $99(26)$ & \\
\hline Non-clinical $(n=42)$ & $25(60)$ & & $29(73)$ & & $12(29)$ & \\
\hline Other $(n=20)$ & $12(60)$ & & $16(80)$ & & $5(25)$ & \\
\hline Political self-characterisation & & $<0.0001$ & & 0.0001 & & 0.04 \\
\hline Very/somewhat conservative $(n=937)$ & $576(61)$ & & $610(66)$ & & $204(22)$ & \\
\hline Independent/moderate $(n=707)$ & $479(68)$ & & $486(69)$ & & $171(25)$ & \\
\hline Very/somewhat liberal or progressive $(n=719)$ & $535(74)$ & & $538(75)$ & & $192(27)$ & \\
\hline
\end{tabular}

making could vary depending on the decision faced, from those with high stakes (eg, major surgery) to more routine circumstances (treatment for allergic rhinitis). In addition, physicians may misjudge a patient's confusion or lack of interest in playing an active role, or may exhibit recall bias when responding to items about barriers to SDM. Moreover, how questions about SDM are framed-in this and in other studies-could lead to discrepant results. Furthermore, these data suggest that a majority of US physicians are fully on-board with SDM despite data from the DECISIONS study and others like it, suggesting that SDM is by no means the norm in routine practice.

\section{Strengths and limitations of this study}

The limited nature of the single-item self-reported measures presented here restrict our inferences. Regarding the substantive findings of the study, several questions persist. It is unclear why physicians disagree with legislating SDM as a means of controlling healthcare costs when they are enthusiastic about it as a cost-containment measure. Do physicians resist infringement on their autonomy generally? Do they resist any potentially punitive regulatory measures? Do they fear 'big brother' government intrusion? It is possible that physicians may not be comfortable with the idea of any behaviours, including SDM, being legislated even if they embrace the potential positive consequences of doing so. Some physicians may fear that using SDM as a means of reducing healthcare costs could tarnish its patient-centered primary objective. These data do not answer whether physicians resist legislating SDM, but only that they oppose such actions as a cost-containment strategy. Ascertaining motivations behind the opinions we report would require further in-depth qualitative work beyond the scope of this survey. In content areas like this, survey items may have been ambiguous despite rigorous pilot testing. For instance, our item, "decision support tools that show cost would be helpful in my practice" was presented in a section on medical decision-making, creating some ambiguity about whether respondent endorsement of this item really constitutes an endorsement of SDM as a cost-containment strategy or a general endorsement of the innovation for patient-centred care. And while self-reported barriers to SDM were not the focus of this survey, we thought it was important to include them as potential key covariates for respondents' judgements about SDM as a costcontainment strategy. For instance, those who feel their work environment is not supportive of SDM may find legislating it the only viable option for change. 
Table 4 Unadjusted and adjusted associations between physician characteristics/attitudes and their views on SDM from bivariate and multivariate logistic regression models

\begin{tabular}{|c|c|c|c|c|c|c|c|c|c|}
\hline & \multicolumn{3}{|c|}{$\begin{array}{l}\text { Very enthusiastic about promoting better } \\
\text { conversations as means to reduce healthcare } \\
\text { costs }\end{array}$} & \multicolumn{3}{|c|}{$\begin{array}{l}\text { Strongly agree decision support tools } \\
\text { showing costs would be helpful in my practice }\end{array}$} & \multicolumn{3}{|c|}{ Promoting SDM should be legislated } \\
\hline & $\begin{array}{l}\text { Unadjusted OR } \\
(95 \% \mathrm{Cl})\end{array}$ & p Value & $\begin{array}{l}\text { Adjusted OR } \\
(95 \% \mathrm{Cl})\end{array}$ & $\begin{array}{l}\text { Unadjusted OR } \\
(95 \% \mathrm{CI})\end{array}$ & p Value & $\begin{array}{l}\text { Adjusted OR } \\
(95 \% \mathrm{Cl})\end{array}$ & $\begin{array}{l}\text { Unadjusted OR } \\
(95 \% \mathrm{CI})\end{array}$ & p Value & $\begin{array}{l}\text { Adjusted OR } \\
(95 \% \mathrm{Cl})\end{array}$ \\
\hline Age (years) & $1.0(0.99$ to 1.01$)$ & & $1.0(0.98$ to 1.01$)$ & $1.0(0.99$ to 1.02$)$ & & $1.0(0.99$ to 1.02$)$ & $0.98^{*}(0.97$ to 0.99$)$ & & $0.98(0.97$ to 1.0$)$ \\
\hline Sex & & $<0.0001$ & & & 0.13 & & & $<0.0001$ & \\
\hline Male & Ref & & Ref & Ref & & Ref & Ref & & Ref \\
\hline Female & $1.7^{\star}(1.4$ to 2.1$)$ & & $1.7^{\star}(1.3$ to 2.0$)$ & $1.2(1.0$ to 1.5$)$ & & $1.1(0.9$ to 1.4$)$ & $1.1(0.9$ to 1.4$)$ & & $1.0(0.8$ to 1.2$)$ \\
\hline Region & & 0.99 & & & 0.002 & & & 0.99 & \\
\hline Midwest & Ref & & Ref & Ref & & Ref & Ref & & Ref \\
\hline South & $1.0(0.8$ to 1.3$)$ & & $1.0(0.8$ to 1.2$)$ & $0.7^{\star}(0.5$ to 0.9$)$ & & $0.7^{*}(0.5$ to 0.9$)$ & $1.0(0.7$ to 1.2$)$ & & $0.9(0.7$ to 1.2$)$ \\
\hline West & $1.0(0.8$ to 1.3$)$ & & $0.9(0.7$ to 1.1$)$ & $1.0(0.8$ to 1.4$)$ & & $0.9(0.7$ to 1.3$)$ & $1.0(0.8$ to 1.4$)$ & & $1.0(0.8$ to 1.3$)$ \\
\hline Northeast & $1.0(0.8$ to 1.3$)$ & & 0.9 (0.7 to 1.2$)$ & $0.7^{*}(0.5$ to 0.9$)$ & & $0.6^{*}(0.5$ to 0.9$)$ & $1.1(0.9$ to 1.5$)$ & & $1.1(0.8$ to 1.5$)$ \\
\hline Primary specialty & & 0.05 & & & 0.33 & & & 0.05 & \\
\hline Primary care & Ref & & Ref & Ref & & Ref & Ref & & Ref \\
\hline Surgery & $0.7^{\star}(0.6$ to 0.9$)$ & & $0.9(0.7$ to 1.1$)$ & $0.8(0.6$ to 1.1$)$ & & $0.9(0.7$ to 1.2$)$ & $0.7^{*}(0.5$ to 0.9$)$ & & $0.7^{*}(0.6$ to 1.0$)$ \\
\hline Procedural specialty & $0.9(0.7$ to 1.1$)$ & & $1.0(0.8$ to 1.2$)$ & $0.8(0.6$ to 1.0$)$ & & $0.8(0.6$ to 1.1$)$ & $1.1(0.9$ to 1.4$)$ & & $1.2(0.9$ to 1.5$)$ \\
\hline Non-procedural specialty & $1.0(0.8$ to 1.3$)$ & & $1.1(0.8$ to 1.4$)$ & $0.8(0.6$ to 1.0$)$ & & $0.8(0.5$ to 1.0$)$ & $1.0(0.8$ to 1.4$)$ & & $1.3(0.8$ to 1.4$)$ \\
\hline Non-clinical & 0.7 (0.4 to 1.2$)$ & & 0.6 (0.3 to 1.2$)$ & $0.8(0.3$ to 1.7$)$ & & 0.7 (0.3 to 1.7$)$ & $1.2(0.6$ to 2.3$)$ & & $1.3(0.7$ to 2.7$)$ \\
\hline Other & 0.7 (0.3 to 1.7$)$ & & 0.7 (0.3 to 1.9$)$ & $0.6(0.2$ to 2.2$)$ & & 0.7 (0.2 to 2.3$)$ & $1.0(0.4$ to 2.7$)$ & & $1.0(0.3$ to 2.8$)$ \\
\hline Political self-characterisation & & $<0.0001$ & & & $<0.0001$ & & & $<0.0001$ & \\
\hline Very/somewhat conservative & Ref & & Ref & Ref & & Ref & Ref & & Ref \\
\hline Independent/moderate & $1.3^{*}(1.1$ to 1.6$)$ & & $1.3^{*}(1.1$ to 1.6$)$ & $1.2(0.9$ to 1.6$)$ & & $1.2(0.9$ to 1.6$)$ & $1.2(0.9$ to 1.5$)$ & & $1.1(0.9$ to 1.4$)$ \\
\hline $\begin{array}{l}\text { Very/somewhat liberal or } \\
\text { progressive }\end{array}$ & $1.8^{*}(1.5$ to 2.3$)$ & & $1.7^{\star}(1.4$ to 2.1$)$ & $2.3^{*}(1.8$ to 2.9$)$ & & $2.2^{*}(1.7$ to 2.9$)$ & $1.3^{*}(1.1$ to 1.7$)$ & & $1.3(1.0$ to 1.6$)$ \\
\hline Practice setting type & & 0.59 & & & 0.07 & & & 0.20 & \\
\hline Small/solo & Ref & & Ref & Ref & & Ref & Ref & & Ref \\
\hline Group/HMO & $1.1(0.9$ to 1.4$)$ & & $1.1(0.8$ to 1.3$)$ & $1.3(1.0$ to 1.7$)$ & & $1.2(0.9$ to 1.7$)$ & $1.0(0.8$ to 1.3$)$ & & $0.9(0.7$ to 1.2$)$ \\
\hline City/state/federal government & $1.2(0.9$ to 1.7$)$ & & $1.1(0.8$ to 1.5$)$ & $1.4^{*}(1.0$ to 2.1$)$ & & $1.4(0.9$ to 2.0$)$ & $1.3(1.0$ to 1.8$)$ & & $1.2(0.8$ to 1.7$)$ \\
\hline Medical school & $1.3(0.7$ to 2.4$)$ & & $1.2(0.6$ to 2.2$)$ & $1.4(0.7$ to 2.7$)$ & & $1.2(0.6$ to 2.5$)$ & $0.7(0.4$ to 1.5$)$ & & $0.6(0.2$ to 1.2$)$ \\
\hline Other non-patient care & $1.5(0.6$ to 3.8$)$ & & $1.1(0.4$ to 3.0$)$ & $2.9^{*}(1.2$ to 7.2$)$ & & $3.0^{*}(1.2$ to 7.8$)$ & 0.7 (0.2 to 2.2$)$ & & $0.7(0.2$ to 2.3$)$ \\
\hline Practice compensation type & & & & & 0.005 & & & 0.14 & \\
\hline Billing only & Ref & 0.06 & Ref & Ref & & Ref & Ref & & Ref \\
\hline Salary/salary plus bonus & $1.2(1.0$ to 1.5$)$ & & $1.2(1.0$ to 1.4$)$ & $1.4^{*}(1.1$ to 1.7$)$ & & $1.4^{*}(1.1$ to 1.7$)$ & $1.2^{*}(1.0$ to 1.5$)$ & & $1.2(0.9$ to 1.4$)$ \\
\hline Other & $1.1(0.6$ to 1.5$)$ & & $1.1(0.8$ to 1.7$)$ & $1.1(0.7$ to 1.8$)$ & & $1.0(0.6$ to 1.6$)$ & $1.1(0.8$ to 1.6$)$ & & $1.0(0.7$ to 1.6$)$ \\
\hline \multicolumn{10}{|c|}{$\begin{array}{l}\text { Major barriers to engaging patients in } \\
\text { SDM } \dagger\end{array}$} \\
\hline Patient confusion & $1.0(0.8$ to 1.2$)$ & 0.89 & $1.0(0.9$ to 1.2$)$ & $1.0(0.8$ to 1.2$)$ & 0.99 & $1.0(0.8$ to 1.3$)$ & $1.0(0.8$ to 1.2$)$ & 0.86 & $1.0(0.8$ to 1.2$)$ \\
\hline $\begin{array}{l}\text { Lack of patient interest in playing } \\
\text { an active role }\end{array}$ & 1.1 (0.9 to 1.3$)$ & 0.50 & $1.1(0.9$ to 1.4$)$ & 1.0 (0.8 to 1.2$)$ & 0.80 & $1.0(0.8$ to 1.3$)$ & $1.0(0.8$ to 1.2$)$ & 0.88 & $1.0(0.8$ to 1.3$)$ \\
\hline $\begin{array}{l}\text { Lack of adequate time with the } \\
\text { patient }\end{array}$ & $1.3^{*}(1.1$ to 1.5$)$ & 0.008 & $1.2(1.0$ to 1.4$)$ & $1.2(0.9$ to 1.4$)$ & 0.16 & 1.1 (0.9 to 1.4$)$ & $1.1(0.9$ to 1.3$)$ & 0.45 & $1.0(0.9$ to 1.3$)$ \\
\hline Administrative burdens & $1.0(0.8$ to 1.2$)$ & 0.92 & $1.0(0.9$ to 1.3$)$ & $1.2(1.0$ to 1.5$)$ & 0.10 & $1.3^{*}(1.0$ to 1.6$)$ & $1.4^{*}(1.1$ to 1.7$)$ & 0.001 & $1.4^{*}(1.1$ to 1.7$)$ \\
\hline Inability to individualise risk & 0.9 (0.8 to 1.2$)$ & 0.61 & 0.9 (0.8 to 1.2$)$ & $1.2(1.0$ to 1.6$)$ & 0.09 & $1.2(0.9$ to 1.6$)$ & $1.5^{*}(1.2$ to 1.8$)$ & 0.0007 & $1.5^{*}(1.2$ to 1.9$)$ \\
\hline
\end{tabular}




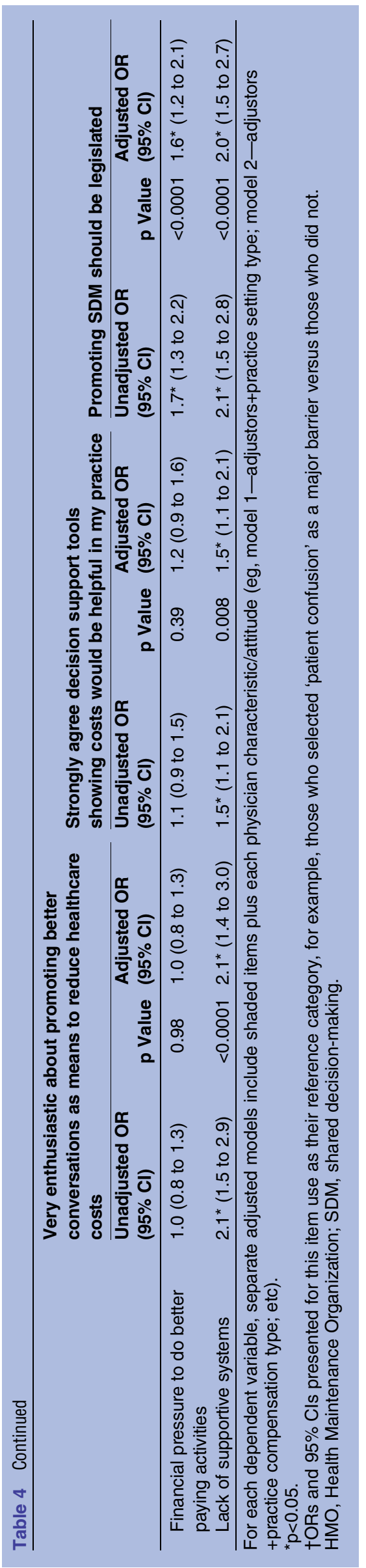

While this cross-sectional survey had a solid response rate, reducing concerns about response bias, its findings should still be treated with caution due to the nature of the topic area. Social desirability may lead physicians to say very glowing things about SDM. Belying their broad endorsement, physicians may hold divergent views of SDM. The survey did not stipulate a definitive definition of SDM. Whether, however, their behaviour follows is what is of ultimate concern and was not addressed in this survey. The contrast between physicians' selfreported enthusiasm and the documented failures to promote SDM in studies of physician behaviour suggest that our respondents may uphold an ideal they themselves do not achieve, or may operate with a different functional definition of SDM. Surveys alone cannot resolve this discrepancy. Although the face validity of our measures (Which of the following is a major barrier to you more actively engaging patients in a process of SDM? Promoting SDM should be legislated as a means of controlling healthcare costs; Decision support tools that show costs would be helpful in my practice; Level of enthusiasm for "promoting better conversations with patients" as a means to promote cost containment) do not evoke a clear social desirability bias, that possibility cannot be excluded. This approach did not (and arguably could not accurately) assess the actual behaviour. The AMA Masterfile is the most comprehensive listing of US physicians, but relies on physician self-report for key practice characteristics. For instance, specialty data listed in the AMA Masterfile lists self-reported specialty that is not verified with specialty boards. The estimates reported here may not fully reflect all the US physician opinion.

\section{CONCLUSIONS AND POLICY IMPLICATIONS}

Since its emergence in the President's Commission 30 years ago, SDM has promoted empowering patients in their care as an intrinsic good. Should policy also support, or require, SDM to achieve cost-savings? Doing so can be justified as a win-win proposition if SDM improves quality and lowers (or stabilises) healthcare spending. Yet, if SDM is viewed-by physicians, patients or both-as primarily aimed at cost control, or as an effort to save money masquerading as quality improvement, then an important, patient-centred tool may well be left in the toolbox unused. These and other unanswered questions about what the appropriate policy rationale for SDM should be will need to be addressed to assure that its ethical ideals are preserved in the coming years. At present, however, it appears most of the physicians are enthusiastic about SDM and see it as a promising avenue for controlling costs.

\section{Author affiliations}

${ }^{1}$ Division of General Internal Medicine, Mayo Clinic, Rochester, Minnesota, USA

${ }^{2}$ Institute for Ethics, American Medical Association, Chicago, Illinois, USA ${ }^{3}$ Division of Endocrinology, Mayo Clinic, Rochester, Minnesota, USA 
${ }^{4}$ Division of Primary Care Internal Medicine, Mayo Clinic, Rochester, Minnesota, USA

${ }^{5}$ Division of Health Care Policy and Research, Mayo Clinic, Rochester, Minnesota, USA

${ }^{6}$ Department of Family Medicine, Mayo Clinic, Rochester, Minnesota, USA

${ }^{7}$ Biomedical Ethics Program, Mayo Clinic, Rochester, Minnesota, USA

${ }^{8}$ Department of General Internal Medicine, University of Michigan Medical

Center, Ann Arbor, Michigan, USA

Contributors JCT, MKW, VMM, BT, JSE, RDS, ML and SDG made substantial contributions to the conception and design of the study. KMH, JCT, SDG and MKW assisted with analysis and interpretation of data. All the authors contributed to drafting the article and revising it critically for important intellectual content. All the authors provided final approval of the version to be published.

Funding This work was funded by a grant from the Faculty Scholars Programme of the Greenwall Foundation, the Mayo Clinic Programme in Professionalism and Ethics, and an Early Career Development Award from the Mayo Clinic Foundation.

Competing interests None.

Ethics approval Mayo Clinic Institutional Review Board.

Provenance and peer review Not commissioned; externally peer reviewed.

Data sharing statement Full dataset and statistical code are available from the corresponding author at tilburt.jon@mayo.edu.

Open Access This is an Open Access article distributed in accordance with the Creative Commons Attribution Non Commercial (CC BY-NC 3.0) license, which permits others to distribute, remix, adapt, build upon this work noncommercially, and license their derivative works on different terms, provided the original work is properly cited and the use is non-commercial. See: http:// creativecommons.org/licenses/by-nc/3.0/

\section{REFERENCES}

1. Charles C, Gafni A, Whelan T. Decision-making in the physician-patient encounter: revisiting the shared treatment decision-making model. Soc Sci Med 1999;49:651-61.

2. President's Commission for the Study of Ethical Problems in Medicine and Biomedical and Behavioral Research. Making health care decisions: a report on the ethical and legal implications of informed consent in the patient-practitioner relationship. Washington, DC: President's Commission for the Study of Ethical Problems in Medicine and Biomedical and Behavioral Research : For sale by the Supt. of Docs., U.S. G.P.O., 1982.
3. Coylewright $\mathrm{M}$, Montori V, Ting HH. Patient-centered shared decision-making: a public imperative. Am J Med 2012;125:545-7.

4. Politi MC, Wolin KY, Legare F. Implementing clinical practice guidelines about health promotion and disease prevention through shared decision making. J Gen Intern Med 2013;28:838-44.

5. Stacey D, Bennett CL, Barry MJ, et al. Decision aids for people facing health treatment or screening decisions. Cochrane Database Syst Rev 2011;(10):CD001431.

6. Arterburn D, Wellman R, Westbrook E, et al. Introducing decision aids at Group Health was linked to sharply lower hip and knee surgery rates and costs. Health Aff (Millwood) 2012;31:2094-104.

7. Fiks AG, Mayne S, Localio AR, et al. Shared decision-making and health care expenditures among children with special health care needs. Pediatrics 2012;129:99-107.

8. Oshima Lee E, Emanuel EJ. Shared decision making to improve care and reduce costs. N Engl J Med 2013;368:6-8.

9. The Patient Protection and Affordable Care Act, 2010.

10. Legare F, Ratte S, Gravel K, et al. Barriers and facilitators to implementing shared decision-making in clinical practice: update of a systematic review of health professionals' perceptions. Patient Educ Couns 2008;73:526-35.

11. Dillman D, Smyth J, Christian L. Internet, mail, and mixed-mode surveys: the tailored design method. 3rd edn. Hoboken, NJ: John Wiley \& Jons, Inc, 2009.

12. Hurst SA, Slowther AM, Forde R, et al. Prevalence and determinants of physician bedside rationing: data from Europe. $J$ Gen Intern Med 2006;21:1138-43.

13. Goold SD, Hofer T, Zimmerman M, et al. Measuring physician attitudes toward cost, uncertainty, malpractice, and utilization review. J Gen Intern Med 1994;9:544-9.

14. Tilburt J, Wynia M, Sheeler R, et al. Views of US physicians about controlling health care costs. JAMA 2013;310:380-8.

15. The American Association for Public Opinion Research. Standard definitions: final dispositions of case codes and outcome rates for surveys. 7th edn. AAPOR, 2011.

16. American Medical Association. Physician characteristics and distribution in the U.S., 2013. Chicago, IL: American Medical Association Bookstore, 2013.

17. Brook RH. Do physicians need a "shopping cart" for health care services? JAMA 2012;307:791-2.

18. Cutler D, Dafny L. Designing transparency systems for medical care prices. N Engl J Med 2011;364:894-5.

19. Farrell KS, Finocchio LJ, Trivedi AN, et al. Does price transparency legislation allow the uninsured to shop for care? J Gen Intern Med 2010;25:110-14.

20. Pauly MV, Burns LR. Price transparency for medical devices. Health Aff (Millwood) 2008;27:1544-53.

21. Rosenthal JA, Lu X, Cram P. Availability of consumer prices from US hospitals for a common surgical procedure. JAMA Intern Med 2013:1-6.

22. Zikmund-Fisher BJ, Couper MP, Singer E, et al. The DECISIONS study: a nationwide survey of United States adults regarding 9 common medical decisions. Med Decis Making 2010;30(Suppl 5):20S-34S 